\title{
Differences in Electrophysical and Gas Sensing Properties of Flame Spray Synthesized $\mathrm{Fe}_{2} \mathrm{O}_{3}\left(\gamma-\mathrm{Fe}_{2} \mathrm{O}_{3}\right.$ and $\left.\alpha-\mathrm{Fe}_{2} \mathrm{O}_{3}\right)$
}

\author{
Dorota Flak ${ }^{1,2, *}$, Artur Braun², Katarzyna A. Michalow², Jan Wyrwa', \\ Magdalena Parlinska-Wojtan ${ }^{3}$, Thomas Graule ${ }^{2,4}$, and Mieczyslaw Rekas ${ }^{1}$ \\ 1 Faculty of Material Science and Ceramics, AGH University of Science and Technology, al. \\ Mickiewicza 30, 30-059 Krakow, Poland \\ ${ }^{2}$ Laboratory for High Performance Ceramics, Empa, Swiss Federal Laboratories for \\ Materials Science and Technology, Überlandstrasse 129, CH-8600 Dübendorf, Switzerland \\ ${ }^{3}$ Institute of Nanotechnology, University of Rzeszow, Al. Rejtana 16a, 35-959 Rzeszow, Poland; \\ Electron Microscopy Center, Empa, Swiss Federal Laboratories for Materials Science and Technology, \\ Überlandstrasse 129, 8600 Dübendorf, Switzerland \\ ${ }^{4}$ Technische Universität Bergakademie Freiberg, D-09596 Freiberg, Germany
}

\begin{abstract}
Nanoscaled $\mathrm{Fe}_{2} \mathrm{O}_{3}$ powders as candidates for gas sensing material for hydrogen detection were synthesized by the high temperature flame spray assisted combustion of ferrocene dissolved in benzene. X-ray diffraction (XRD) and selected area electron diffraction (SAED) show that the as prepared nanopowder consists of maghemite $\left(\gamma-\mathrm{Fe}_{2} \mathrm{O}_{3}\right)$ with low crystallinity. Thermal post-treatment causes a phase transformation towards hematite $\left(\alpha-\mathrm{Fe}_{2} \mathrm{O}_{3}\right)$ accompanied by an increase in the crystallinity. Upon exposure to air and hydrogen at elevated temperatures, both phases show a significant variation of conductivity and activation energy-as evidenced by impedance spectra-and thus a favorable sensor response, surpassing even that of flame-synthesized nanocrystalline tin dioxide. The conductivity has been identified as of electronic origin, affected by trap states located in the region adjacent to grain boundaries. Quantitative analysis of the impedance spectra with equivalent circuits shows that the conductivity is thermally activated and affected by the interaction of hydrogen with the sensor material. The calculated Debye screening length of $\gamma-\mathrm{Fe}_{2} \mathrm{O}_{3}$ and $\alpha-\mathrm{Fe}_{2} \mathrm{O}_{3}$ is about $27 \mathrm{~nm}$ and $16 \mathrm{~nm}$, respectively, what contributes significantly to the sensitivity of the material. $\gamma-\mathrm{Fe}_{2} \mathrm{O}_{3}$ and $\alpha-\mathrm{Fe}_{2} \mathrm{O}_{3}$ exhibit high sensor response towards hydrogen in a wide concentration range. $\gamma$ - $\mathrm{Fe}_{2} \mathrm{O}_{3}$ shows $n$-type semiconducting behavior up to $573 \mathrm{~K} . \alpha-\mathrm{Fe}_{2} \mathrm{O}_{3}$ shows $p$-type semiconducting behavior, as reflected in the dynamic changes of the resistivity. For both sensor materials, $523 \mathrm{~K}$ was the optimal operating temperature.
\end{abstract}

Keywords: Maghemite, Hematite, Impedance Spectroscopy, Gas Sensor, Nanopowder.

\section{INTRODUCTION}

Ferric oxide $\left(\mathrm{Fe}_{2} \mathrm{O}_{3}\right)$ is one of the semiconducting metal oxides, which is of great interest as solid state gas sensor. ${ }^{1-10} \alpha-\mathrm{Fe}_{2} \mathrm{O}_{3}$ hematite and $\gamma-\mathrm{Fe}_{2} \mathrm{O}_{3}$ maghemite are two crystal phases of the ferric oxide, which are mainly investigated for gas sensor applications as they have a narrow band gap, good chemical stability, low cost and broad applications. Recently, switching of conductivity type, which depends on the material doping, measurement conditions and chosen gas agent, has attracted considerable attention. This effect can have significant impact on the

\footnotetext{
- Author to whom correspondence should be addressed.
}

gas sensing properties of iron oxide. Lee et al. ${ }^{11}$ reported about the $p$-type conductivity of $\alpha$ - $\mathrm{Fe}_{2} \mathrm{O}_{3}$ nanowires with induced oxygen vacancies, which switched the conductivity to $n$-type after annealing in reducing atmosphere at low temperature. Gurlo et al. ${ }^{2}$ showed for $\alpha-\mathrm{Fe}_{2} \mathrm{O}_{3}$ that by changing the gas composition and operating temperature it was possible to control the crossover of conductivity from $p$-type to $n$-type. Vasiliev et al. ${ }^{8}$ showed that doping of $\alpha-\mathrm{Fe}_{2} \mathrm{O}_{3}$ with low concentrations of $\mathrm{ZnO}$, caused changes of the conductivity from $p$-type to $n$-type, under exposure to reducing gases.

As discussed in many reports concerning $\mathrm{Fe}_{2} \mathrm{O}_{3}$, its gas sensing properties can be greatly influenced by the 
preparation and modification method..$^{3,10,12-14}$ In order to obtain relevant material for gas sensing applications it is necessary to precisely control its phase composition and crystallinity. Flame spray synthesis (FSS) satisfies this requirement. The high temperature flame spray process is a facile synthesis technique for the preparation of semiconductor metal oxides as the next generation of high performance nanopowders for gas sensing applications. ${ }^{15-17}$ Nanoscaled size, predominantly uniform, nonporous structure of the particles and a high degree of crystallinity allow for a high and stable gas sensor signal, as well as a short response time.

In the present paper we report on electrophysical properties and hydrogen sensing of two crystallographically different flame-synthesized $\mathrm{Fe}_{2} \mathrm{O}_{3}$ nanopowders. The main focus was on investigation of the electrical properties of the semiconducting material with the aim to understand the interaction of the nanocrystalline forms of $\mathrm{Fe}_{2} \mathrm{O}_{3}$ with air and reducing atmosphere at various temperatures. We demonstrated the relative changes of the resistivity of iron oxides under exposure to reference air and to reducing atmosphere. The nature of the conduction processes and mechanism of the gas/solid interactions was discussed. The flame-synthesized and post-treated $\mathrm{Fe}_{2} \mathrm{O}_{3}$ exhibited high sensor response towards hydrogen, which can compete with already reported iron oxide-based gas sensors.

\section{EXPERIMENTAL DETAILS}

\subsection{Preparation of Iron Oxides}

$\mathrm{Fe}_{2} \mathrm{O}_{3}$ nanopowder was prepared by one-step flame spray synthesis (FSS) using $0.5 \mathrm{M}$ solution of ferrocene $\left(\mathrm{Fe}\left(\mathrm{C}_{5} \mathrm{H}_{5}\right)_{2}, 98 \%\right.$, Sigma-Aldrich $)$ in benzene $\left(\mathrm{C}_{6} \mathrm{H}_{6}\right.$, $99.9 \%$, Sigma-Aldrich). Details of the FSS setup are reported elsewhere. ${ }^{18,19} 0.5 \mathrm{M}$ precursor solution was pumped (flow rate of precursor $0.250 \mathrm{~cm}^{3} \mathrm{~s}^{-1}$ ) by the syringe pump through a capillary tube and then atomized by a gas-assisted external mixing nozzle by oxygen (flow rate of dispersion gas was $583 \mathrm{~cm}^{3} \mathrm{~s}^{-1}$ ). This combustible aerosol was ignited by six acetylene-oxygen flamelets (flow rates: $\mathrm{C}_{2} \mathrm{H}_{2}=217 \mathrm{~cm}^{3} \mathrm{~s}^{-1}, \mathrm{O}_{2}=283 \mathrm{~cm}^{3} \mathrm{~s}^{-1}$ ). The as-synthesized particles were collected in a bag house filter system and representative samples (1-2 g) were collected on a glass fiber filter (GF/A 150, Whatman) via a bypass using vacuum pumps.

As-synthesized $\mathrm{Fe}_{2} \mathrm{O}_{3}$ was subjected to a thermal posttreatment (Nabertherm furnace) at $823 \mathrm{~K}$ for 30 minutes in air (no heating and no cooling periods) in order to induce the phase transformation towards hematite according to Eq (1):

$$
\gamma-\mathrm{Fe}_{2} \mathrm{O}_{3} \stackrel{\approx 823 \mathrm{~K}}{\longrightarrow} \alpha-\mathrm{Fe}_{2} \mathrm{O}_{3}
$$

As a reference material, nanosized $\mathrm{SnO}_{2}$ powder was synthesized by FSS from $5 \mathrm{M}$ tin-tetramethyl solution $\left(\mathrm{Sn}\left(\mathrm{CH}_{3}\right)_{4}, 95 \%\right.$ Sigma-Aldrich) in ethanol
$\left(\mathrm{C}_{2} \mathrm{H}_{5} \mathrm{OH}, 99.9 \%\right.$, Sigma Aldrich). $5 \mathrm{M}$ precursor solution was pumped by the syringe pump with flow rate of $0.033 \mathrm{~cm}^{3} \mathrm{~s}^{-1}$.

\subsection{Nanopowders Characterization}

The specific surface area (SSA) of as-synthesized powders was determined from a 5-point $\mathrm{N}_{2}$ adsorption isotherm obtained from Brunauer-Emmett-Teller (BET) measurements (Beckman-Coulter SA3100). Prior to analysis the powder samples were dried at $453 \mathrm{~K}$ for $120 \mathrm{~min}$ under synthetic air with a flow rate of $0.133 \mathrm{~cm}^{3} \mathrm{~s}^{-1}$ in order to remove physisorbed water from the surface. X-ray diffraction (XRD) was performed with a Philips PANalytical $X$ 'Pert Pro MPD diffractometer using $\mathrm{Cu} \mathrm{K} \alpha$ filtered radiation over a $2 \theta$ range from $20^{\circ}$ to $80^{\circ}$. The XRD results were used to determine the crystallinity and the phase composition. Phase identification was carried out using the Inorganic Crystal Structure Database (ICSD). Particle size, shape and morphology of the particles were investigated by transmission electron microscopy (TEM). The particle size distribution was determined by statistical image analysis. TEM images were recorded either with a highresolution and analytical STEM-TEM JEOL 2200FS or high-resolution and conventional TEM Philips CM30. The powder samples for TEM measurements were deposited onto carbon coated copper grids (Plano $\mathrm{GmbH}$ ).

\subsection{Impedance Measurements}

$\mathrm{AC}$ impedance spectra were recorded using a frequency response analyzer Solartron model 1260 and dielectric interface Solartron model 1296 connected to a potentiostat. The impedance spectra were recorded over a frequency range of $100-10 \mathrm{MHz}$ with a $20 \mathrm{mV}$ sinusoidal amplitude and quantitatively analysed with ZView software (Scribner Associates, Inc.). For measurements discshaped bulk samples with diameter of $5 \mathrm{~mm}$ and thickness of ca. $2 \mathrm{~mm}$ were prepared, containing ca. $100 \mathrm{mg}$ of powder and compacted under the pressure of 1-1.5 $\mathrm{MPa}$. The samples were placed in a tube furnace equipped with gas and carrier inlet and temperature control. The impedance measurements were carried out with the samples exposed to synthetic air $\left(20 \% \mathrm{O}_{2}+80 \% \mathrm{~N}_{2}\right.$, marked in the corresponding figures as Air, and to a gas mixture of $90 \%$ $\mathrm{Ar}+10 \% \mathrm{H}_{2}$, marked as $\mathrm{Ar}+10 \% \mathrm{H}_{2}$ at constant flow rate of $0.133 \mathrm{~cm}^{3} \mathrm{~s}^{-1}$. Spectra were collected in the temperature range from $298 \mathrm{~K}$ to $673 \mathrm{~K}$, with steps of roughly $100 \mathrm{~K}$. The measurements were initiated after equilibration of gas atmosphere and temperature.

\subsection{Gas Sensor Measurements}

The samples for the gas sensor measurements were prepared in the form of discs as in the case of impedance measurements. The samples were mounted in a platinum

J. Nanosci. Nanotechnol. 12, 6401-6411, 2012 
holder enclosed within the measurement chamber. The performance of as-assembled sensor, which operates as a resistive element was studied by DC measurements. The DC measurements were carried out inside a closed quartz tube placed coaxially inside a resistively heated furnace, with remotely controlled temperature. The gas environment inside the chamber was provided with inlet and outlet leads. The gas delivery system was based on mass flow controllers (MKS Instruments). The concentration of the analyte gas was varied by applying the proper ratio of the gases at the constant flow rate. The experimental setup was equipped with custom-built LabView-based control and data acquisition software. The gas exposure time were fixed for each gas pulse. The sensor response $(S)$ is defined as the ratio of resistance in the presence of target gas $R$ to the resistance in the reference atmosphere at constant voltage $(2 \mathrm{~V}), R_{o}$, i.e., $S=R / R_{\mathrm{o}}$.

\section{RESULTS AND DISCUSSION}

\subsection{Structural and Morphological Characterization}

$\mathrm{Fe}_{2} \mathrm{O}_{3}$ in two forms, as-synthesized and after posttreatment were investigated with respect to hydrogen sensing properties. As-synthesized $\mathrm{Fe}_{2} \mathrm{O}_{3}$ powder was brownish and consisted of low crystallinity maghemite $(\gamma$ $\mathrm{Fe}_{2} \mathrm{O}_{3}$ ). Thermal post-treatment of as-synthesized $\mathrm{Fe}_{2} \mathrm{O}_{3}$ at $\sim 823 \mathrm{~K}$ completed the phase transformation to hematite $\left(\alpha-\mathrm{Fe}_{2} \mathrm{O}_{3}\right)$, upon which the color changed to orangered. $^{20}$ The crystallographic structure parameters of assynthesized and post-treated powder are presented in Table I. The X-ray diffractograms of as-synthesized and post-treated $\mathrm{Fe}_{2} \mathrm{O}_{3}$ powders are displayed in Figure 1 . The as-synthesized $\mathrm{Fe}_{2} \mathrm{O}_{3}$ consists of low crystallinity maghemite (non-stoichiometric $\mathrm{Fe}_{2} \mathrm{O}_{3}$; ICSD Collection Code 87119). The $\mathrm{Fe}_{2} \mathrm{O}_{3}$ after post-treatment exhibits a structure of $\mathrm{Fe}_{2} \mathrm{O}_{3}$ hematite (ICSD Collection code 040142 ). Both XRD patterns of $\gamma-\mathrm{Fe}_{2} \mathrm{O}_{3}$ and $\alpha-\mathrm{Fe}_{2} \mathrm{O}_{3}$ (Fig. 1) were compared to diffractograms in Ref. [21], showing $\gamma-\mathrm{Fe}_{2} \mathrm{O}_{3}$ in soot obtained by combustion of ferrocene in diesel fuel. The Bragg reflections of the assynthesized $\mathrm{Fe}_{2} \mathrm{O}_{3}$ are distinctly broadened, but become significantly sharper after post-treatment, confirming the increase of crystallinity. The crystallite sizes $d_{\mathrm{XRD}}$ as determined by Scherrer's formula are summarized in Table I.

The TEM images of as-synthesized (Figs. 2(a-c)) and post-treated $\mathrm{Fe}_{2} \mathrm{O}_{3}$ powders (Figs. 2(d, e)) show that assynthesized $\gamma-\mathrm{Fe}_{2} \mathrm{O}_{3}$ particles are nano-sized and partly

Table I. Structural parameters of $\mathrm{Fe}_{2} \mathrm{O}_{3}$ nanopowders.

\begin{tabular}{lcccc}
\hline Powder name & $\mathrm{SSA} / \mathrm{m}^{2} \mathrm{~g}^{-1}$ & $d_{\mathrm{XRD}} / \mathrm{nm}$ & $d_{\mathrm{BET}} / \mathrm{nm}$ & $d_{\mathrm{TEM}} / \mathrm{nm}$ \\
\hline $\boldsymbol{\gamma}-\mathrm{Fe}_{2} \mathrm{O}_{3}$ & 95.45 & 7.14 & 12.83 & 11.98 \\
$\alpha-\mathrm{Fe}_{2} \mathrm{O}_{3}$ & 25.30 & 29.38 & 45.00 & $\sim 42$ (width) $^{a}$ \\
& & & & $\sim 157($ length) \\
\hline
\end{tabular}

arefers to worm-like structures.

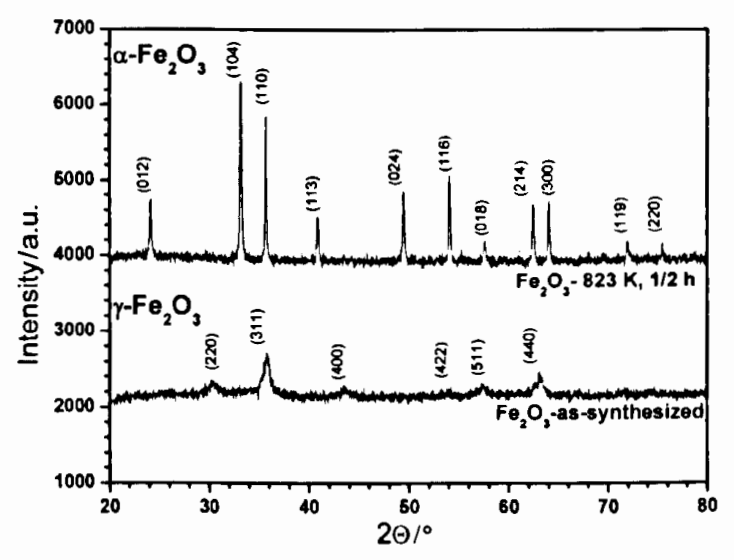

Fig. 1. XRD patterns of as-synthesized and post-treated $\mathrm{Fe}_{2} \mathrm{O}_{3}$.

aggregated, some of the particles are of hexagonal shape. The nanopowders show polycrystalline character as observed in the Figure 2(b). The visible particles are not single crystalline, but contain multiple crystallites as observed from lattice fringes from crystallites with different orientation within the particle. The lattice fringes are observed on a significant number of particles, which underlines the partially crystalline nature of the assynthesized $\mathrm{Fe}_{2} \mathrm{O}_{3}$, in line with the broad Bragg reflections (Fig. 1). Only the minor part of the small particles from the as-synthesized nanopowders appears amorphous. The average particle size $\left(d_{\text {TEM }}\right)$ was roughly $12 \mathrm{~nm}$ for assynthesized $\mathrm{Fe}_{2} \mathrm{O}_{3}$. In the case of post-treated powder, a substantial increase in particles size is observed caused by sintering effect with formation of prolate worm-like structures with an arithmetic average length of roughly $157 \mathrm{~nm}$ and an average arithmetic width of roughly $42 \mathrm{~nm}$, as found by statistical analysis of the TEM micrographs. Particle necking is a desirable feature in powders used for gas sensor application. The selected area electron diffraction (SAED) patterns consisted of sharp rings containing spots, which confirmed the crystalline character of the powder. The formation of distinct spots in the SAED pattern of the post-treated powder (Fig. 2(e)) suggests also a significant increase of the individual crystallite size. The indexing of the reflections from the SAED patterns led to a good match with the Bragg reflections found by XRD: maghemite phase for as-synthesized $\mathrm{Fe}_{2} \mathrm{O}_{3}$ and hematite phase for post-treated $\mathrm{Fe}_{2} \mathrm{O}_{3}$. The average particle size $d_{\text {TEM }}$ and the geometric standard deviation $\sigma_{\mathrm{g}}$ were derived from log-probability plots. We recall for the reader that the geometric standard deviation $\sigma_{\mathrm{g}}$ is calculated accordingly to the Ref [22]. The calculated particle diameter $d_{\text {TEM }}$ was $11.98 \mathrm{~nm}$ and the geometric standard deviation $\sigma_{\mathrm{g}}$ was 1.33. The calculations were based on the measurements of diameters of approximately 150 selected particles. Particle size distribution (PSD) curves and calculated geometric standard deviation $\sigma_{\mathrm{g}}$ presented in Figure 3 are slightly 
Fig. 2. TEM images and SAED patterns of as-synthesized $-\mathrm{Fe}_{2} \mathrm{O}_{3}(\mathrm{a}, \mathrm{b}, \mathrm{c})$ and post-treated $\alpha$ - $\mathrm{Fe}_{2} \mathrm{O}_{3}$ (d, e). Note the different scalemarkers in the bright field micrographs.
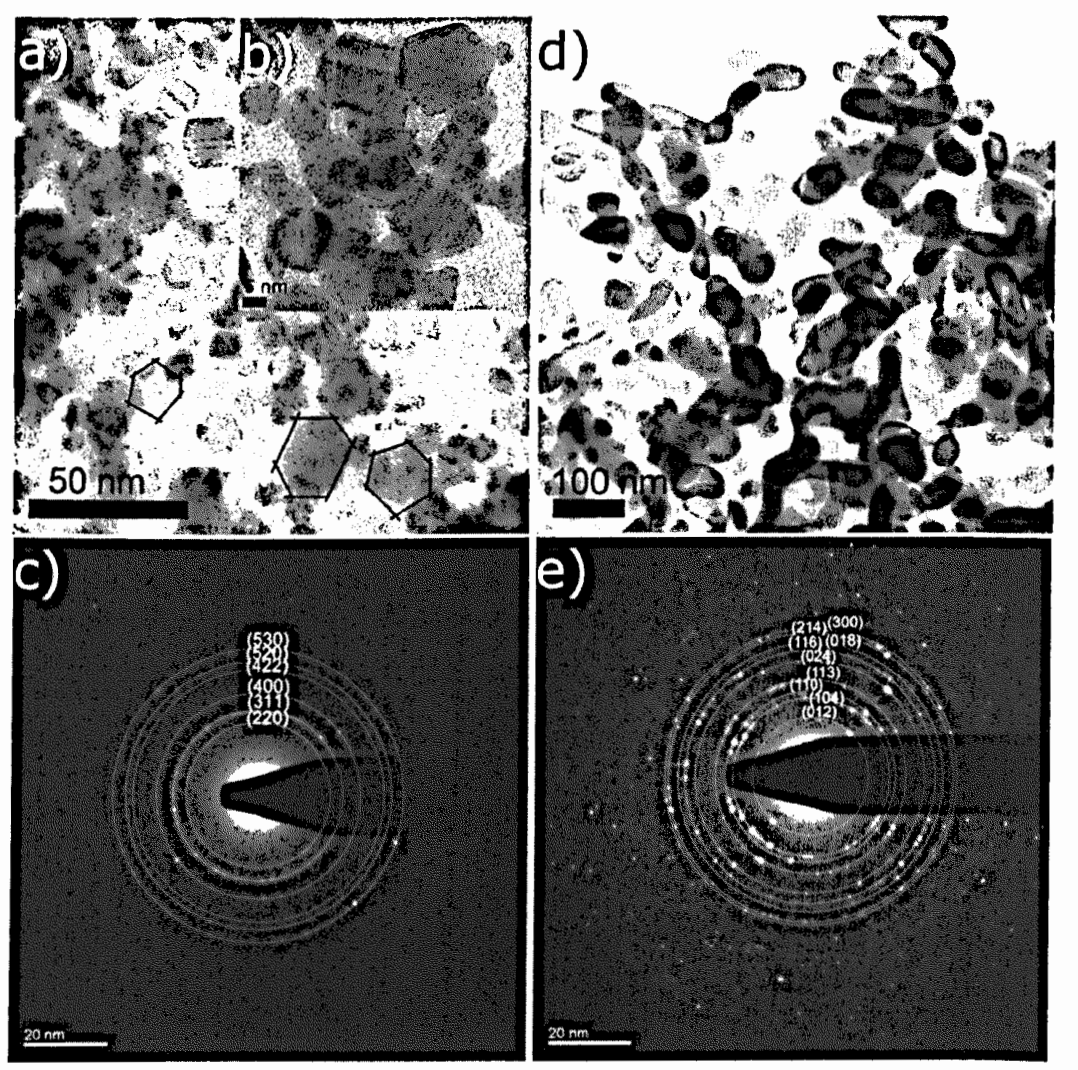

smaller than common flame derived particle size distribution, possibly because a highly volatile precursor was used, which may lead to a narrower PSD. The comparison of the particle size derived from BET and TEM, and the crystallite size derived from XRD measurements of the polycrystalline nanopowders, showed good agreement between those values. Given the dissimilar physical nature of these methods, the agreement is actually surprising. Confident particle size determination based on TEM image analysis

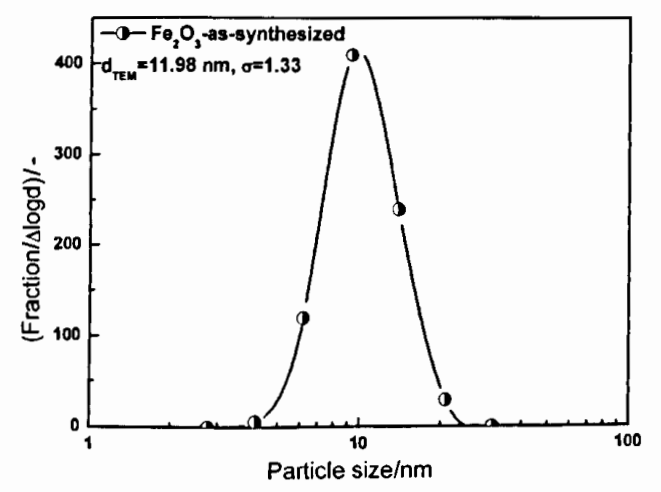

Fig. 3. Frequency distribution curve of as-synthesized $\gamma-\mathrm{Fe}_{2} \mathrm{O}_{3}$ nanopowder calculated from TEM micrographs. for the post-treated nanopowder was not possible because the particles were connected by the necking.

\subsection{Electrical Properties of the Sensor Pellet}

The AC impedance measurements of bulk disc-shaped samples of as-synthesized $\gamma-\mathrm{Fe}_{2} \mathrm{O}_{3}$ and post-treated $\alpha-\mathrm{Fe}_{2} \mathrm{O}_{3}$ were carried out to evaluate whether materials exhibit changes of the electrical properties due to exposure first to ambient air and then to reducing atmosphere. Based on least square fitting the equivalent circuits were proposed. The impedance planes $\left(Z^{\prime \prime}\right.$ vs $\left.Z^{\prime}\right)$ of both polymorphic forms of $\mathrm{Fe}_{2} \mathrm{O}_{3}$ as a function of temperature $(298 \mathrm{~K}$ to $673 \mathrm{~K}$ ) in synthetic air and hydrogen atmosphere ( $\mathrm{Ar}$ $+10 \% \mathrm{H}_{2}$ ) are shown in Figures 4 and 5 . Under the synthetic air atmosphere $\gamma-\mathrm{Fe}_{2} \mathrm{O}_{3}$ and $\alpha-\mathrm{Fe}_{2} \mathrm{O}_{3}$ exhibited typical impedance spectra (Figs. 4(c, d), and Figs. 5(c, d)), one distinct depressed semicircle at high frequencies, followed by a less distinct semicircle at lower frequencies, except for the measurement carried out at ambient temperature (298 K) (Fig. 4(c) and Fig. 5(c)). In turn, under hydrogen atmosphere impedance spectra were obtained up to $473 \mathrm{~K}$ for both samples (Figs. 4(a, b) and Figs. 5(a,b)). During the analysis of the impedance spectra it turned out that for

J. Nanosci. Nanotechnol. 12, 6401-6411, 2012 

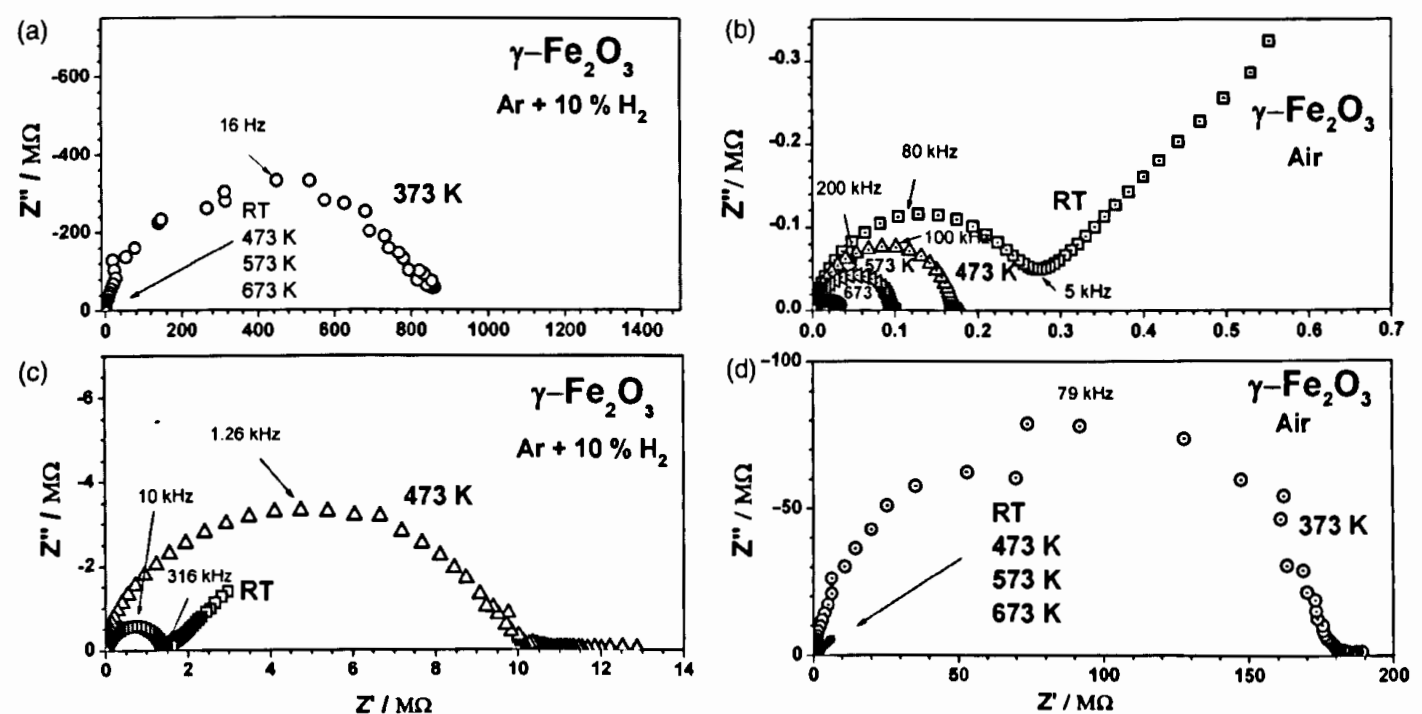

Fig. 4. Complex impedance plots $\left(Z^{\prime \prime}\right.$ vs. $\left.Z^{\prime}\right)$ for $\gamma$-Fe $\mathrm{O}_{2} \mathrm{O}_{3}$ samples under hydrogen atmosphere $(\mathrm{Ar}+10 \% \mathrm{H})(\mathrm{a}, \mathrm{b})$ and synthetic air $(\mathrm{c}, \mathrm{d})$.

$T>473 \mathrm{~K}$ it was more appropriate to present the data as admittance spectra $\left(Y^{\prime \prime}\right.$ vs $\left.Y^{\prime}\right)$ (Figs. 6(a, b)).

Nyquist plots were fitted with the equivalent circuits. For the interpretation of the experimental impedance spectra equivalent circuits composed of an inductive element $(\mathrm{L})$ in series with a parallel mode containing a resistor (R) and a constant phase element (CPE) was proposed (Fig. 7(a)). The admittance was fitted with a simplified equivalent circuit composed of resistor (R) and inductive element (L) in series mode (Fig. 7(b)). The $\mathrm{R}$ element is accounting for the granular and/or intergranular resistance of the sensor material. The CPE element is used here to account for a disorder in the charge diffusion dynamics on particles or between particles caused by material inhomogeneity, which can be typically expected in a polycrystalline material (Fig. 2). The inductive element $\mathrm{L}$ mentioned here is not only due to cable connections, but also originates from space charge polarization regions and adsorption processes near the electrode region, which is in agreement with the results presented in Refs. [23]-[25]. At high temperature and after long exposure to reducing gas atmosphere, the space charge region and thus oxygen ion species are completely removed by the interacting gas, and electrons are injected into the conduction band of the metal oxide, affecting the material's conductivity. ${ }^{26-28}$ The impedance
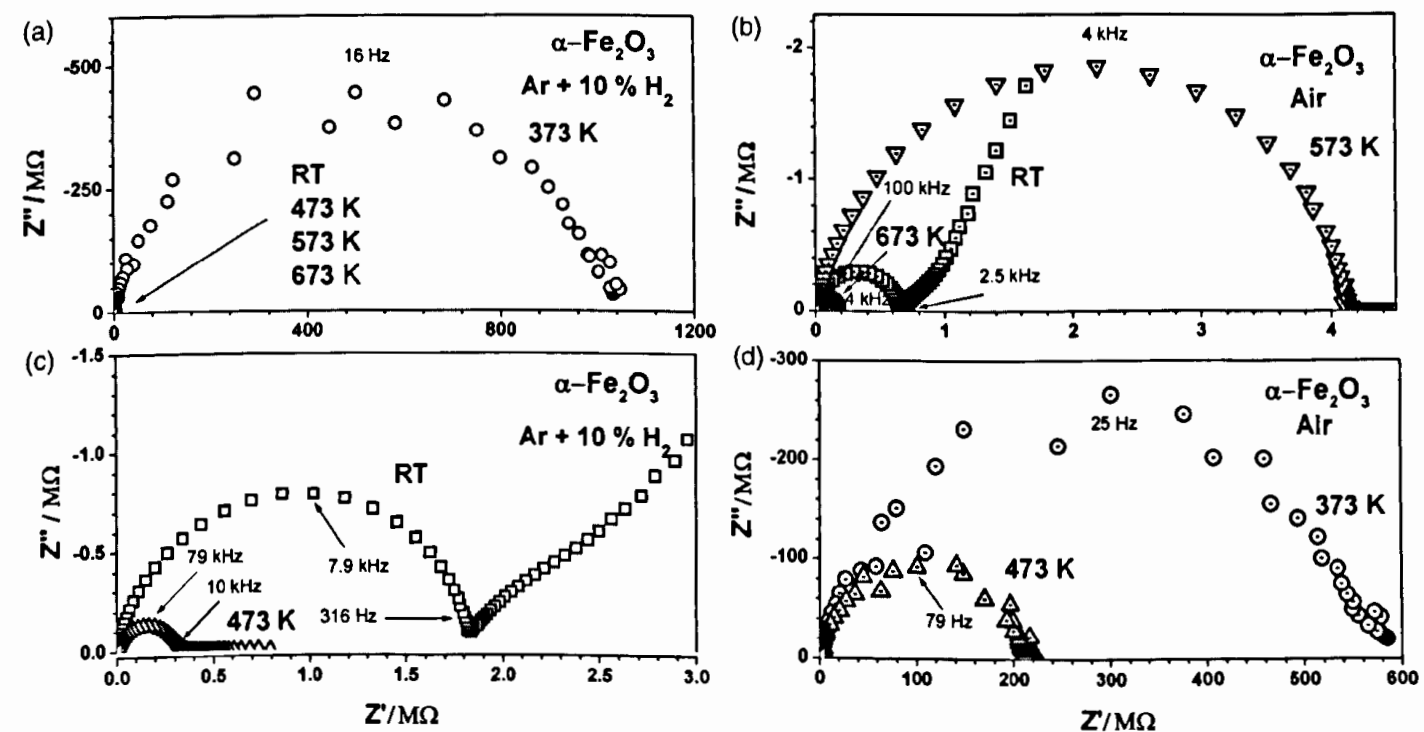

Fig. 5. Complex impedance plots $\left(Z^{\prime \prime}\right.$ vs. $\left.Z^{\prime}\right)$ for $\alpha-\mathrm{Fe}_{2} \mathrm{O}_{3}$ samples under hydrogen atmosphere $\left(\mathrm{Ar}+10 \% \mathrm{H}_{2}\right)(\mathrm{a}, \mathrm{b})$ and synthetic air (c, d). 

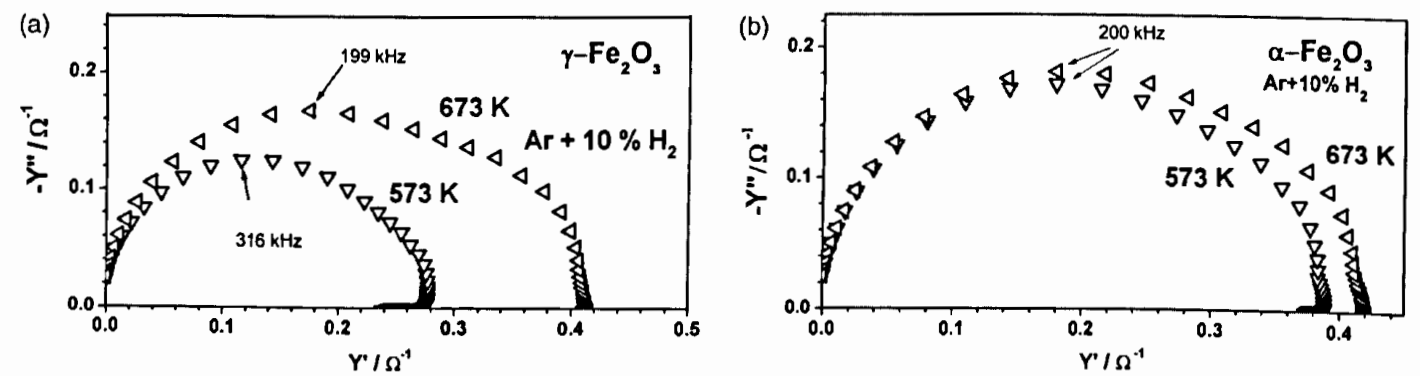

Fig. 6. Complex admittance plots $\left(Y^{\prime \prime}\right.$ vs. $\left.Y^{\prime \prime}\right)$ for $\gamma-\mathrm{Fe}_{2} \mathrm{O}_{3}$ (a) and $\alpha-\mathrm{Fe}_{2} \mathrm{O}_{3}$ (b) samples underhydrogen atmosphere $\left(\mathrm{Ar}+10 \% \mathrm{H}_{2}\right)$.

spectra recorded at ambient temperature in synthetic air and hydrogen atmosphere display one semicircle at high frequencies and a trace at low frequency. Such behavior was previously reported for metal oxides, but the interpretation was controversial. ${ }^{29-32}$ The second semicircle can be interpreted by an equivalent circuit composed of a parallel connection of CPE and $R$, whereas a straight line can be fitted by a Warburg Impedance element. Both cases indicate that at ambient temperature the contribution from the migration of ions towards the electrode, sample contact region and accumulation of ionic charges prevails over the electron transfer, what was already reported for $\mathrm{Fe}_{2} \mathrm{O}_{3}{ }^{31}$ This behavior is associated with adsorbed water molecules on active sites on nanoparticles. In our study, the focus is on the high frequency semicircle (the ranges of the frequency shown in Figures 4 and 5, 6 with the arrows), which originates from the grain boundaries. This contribution is particularly significant for samples with very small grains (nano-size from maghemite and hematite powders), because those provide then a relatively large portion of grain boundaries (Table I), and thus dominate the electric transport. Orton and Powell in Ref. [33] discussed in detail the particle size and grain boundary effect with respect to the electrical properties of polycrystalline semiconducting ceramic materials. They pointed out that if the size of the particle is close to or smaller than the Debye screening length $\left(\lambda_{D}\right)$ the electrical properties of the material are strongly affected by the grain boundaries and particularly by the trap states within the grain interfaces, which lead to the inter-grain band-bending. This will bring significant improvement of the sensitivity of the material. Thus, we calculated the Debye length in as-synthesized maghemite

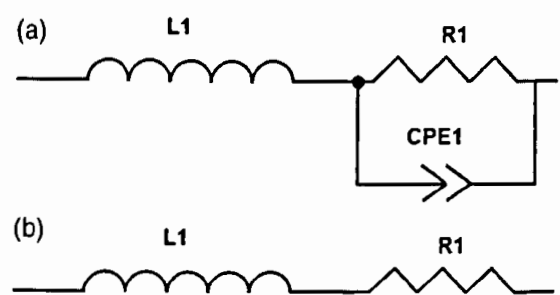

Fig. 7. Equivalent circuits applied for fitting impedance (a) and admittance (b) spectra. and post-treated hematite nanoparticles according to the following equation:

$$
\lambda_{D}=\sqrt{\frac{\varepsilon_{0} \varepsilon_{r} k T}{q^{2} n_{c}}}
$$

where: $\varepsilon_{0}$ is the dielectric constant of free space, $\varepsilon_{\mathrm{r}}$ is the dielectric constant of the material as determined from our impedance data (after Refs. [30], [34]) $k$ is the Boltzmann constant, $T$ is the absolute temperature, $q$ is the electrical charge of the carrier and $n_{c}$ is the carrier concentration (was taken as $1.3 \times 10^{24}$ after Ref. [35]). The thus calculated Debye length is $\lambda_{\mathrm{D}} \approx 16 \mathrm{~nm}$ for our maghemite and $\lambda_{D} \approx 27 \mathrm{~nm}$ for hematite nanoparticles. This means that the assumption of particle size $d \leq \lambda_{\mathrm{D}}$ is fulfilled for the as-synthesized maghemite nanoparticles. The electrons not only in the regions adjacent to the grain boundaries but also in the bulk will be completely depleted when exposed to the oxygen containing atmosphere (air). In the case of hematite nanoparticles the dependence of $d>\lambda_{\mathrm{D}}$ is observed. Thus, for the hematite nanoparticles we also calculated the contribution of the bulk fraction (particle core) to the depleted layer fraction (particle shell) as a ratio $V_{\text {core }} / V_{\text {shell }}$. It is evidenced that although the size of hematite particles is larger than $\lambda_{\mathrm{D}}$ the contribution of the core fraction is only about $3 \%$. This can vary taking into account the particle size distribution (see Table I). The schematic representation of the grains/crystallites of $\mathrm{Fe}_{2} \mathrm{O}_{3}$ is shown in Figure 8. Based on the following calculation
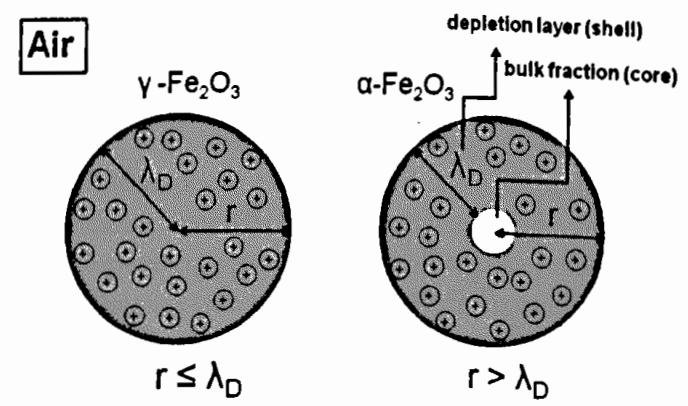

Fig. 8. Schematic representation of the grains/crystallites of $\mathrm{Fe}_{2} \mathrm{O}_{3}$ under air atmosphere: $\gamma-\mathrm{Fe}_{2} \mathrm{O}_{3}$-grains/crystallites smaller or comparable to $\lambda_{\mathrm{D}}, \alpha-\mathrm{Fe}_{2} \mathrm{O}_{3}-$ grains/crystallites larger than $\lambda_{\mathrm{D}}$ with bulk fraction. 
Flak et al. Differences in Electrophysical and Gas Sensing Properties of Flame Spray Synthesized $\mathrm{Fe}_{2} \mathrm{O}_{3}\left(\gamma-\mathrm{Fe}_{2} \mathrm{O}_{3}\right.$ and $\alpha$ - $\left.\mathrm{Fe}_{2} \mathrm{O}_{3}\right)$

Table II. The least square fit results for the complex impedance of $\boldsymbol{\gamma}-\mathrm{Fe}_{2} \mathrm{O}_{3}$ sensor under different temperatures and synthetic air atmosphere. Unit description: K-Kelvin, H-Henry, F-Farad, rad-radian, $\Omega$-ohm.

\begin{tabular}{lccc}
\hline Temperature/K & $\begin{array}{c}\text { Equivalent circuit } \\
\text { elements }\end{array}$ & Value/unit & Error/\% \\
\hline 373 & L1 & $1.40 \mathrm{E}-5 / \mathrm{H}$ & 2.93 \\
& CPE1-T & $1.06 \mathrm{E}-11 / \mathrm{F}$ & 2.07 \\
& CPE1-P & $0.94 / \mathrm{rad}$ & 0.14 \\
R1 & $1.78 \mathrm{E} 8 / \Omega$ & N/A \\
473 & L1 & $8.55 \mathrm{E}-5 / \mathrm{H}$ & 3.03 \\
& CPE1-T & $2.68 \mathrm{E}-11 / \mathrm{F}$ & 2.25 \\
& CPE1-P & $0.92 / \mathrm{rad}$ & 0.14 \\
& RI & $1.70 \mathrm{E} 5 / \Omega$ & N/A \\
573 & L1 & $1.69 \mathrm{E}-5 / \mathrm{H}$ & 5.54 \\
& CPE1-T & $3.33 \mathrm{E}-11 / \mathrm{F}$ & 3.43 \\
& CPE1-P & $0.93 / \mathrm{rad}$ & 0.22 \\
& R1 & $3.25 \mathrm{E} 4 / \Omega$ & N/A \\
673 & Ll & $2.36 \mathrm{E}-5 / \mathrm{H}$ & 4.91 \\
& CPE1-T & $2.89 \mathrm{E}-11 / \mathrm{F}$ & 3.38 \\
& CPEl-P & $0.92 / \mathrm{rad}$ & 0.23 \\
& R1 & $9.62 \mathrm{E} 4 / \Omega$ & N/A \\
\hline
\end{tabular}

we consider the high frequency semicircle as a contribution of the regions adjacent to grain boundaries, where the electron exchange takes place.

The results of least square fits based on the generally accepted equivalent circuits (see refs 23-25, 29-32) are summarized in Tables II, III, IV and $\mathrm{V}$ for $\gamma-\mathrm{Fe}_{2} \mathrm{O}_{3}$ and $\alpha-\mathrm{Fe}_{2} \mathrm{O}_{3}$ samples exposed to synthetic air and hydrogen atmosphere, respectively.

A significant change in the resistance is observed along with the temperature and the introduced atmosphere, while the diffusion-related capacitance CPE varies only marginally. This also suggests that the main changes take place within the inter-granular resistance. The gas adsorption processes and resulting changes of the electrical

Table III. The least square fit results for the complex impedance of $\boldsymbol{\gamma}-\mathrm{Fe}_{2} \mathrm{O}_{3}$ sensor under different temperatures and hydrogen atmosphere.

\begin{tabular}{|c|c|c|c|}
\hline Temperature/K & $\begin{array}{l}\text { Equivalent circuit } \\
\text { elements }\end{array}$ & Value/unit & Error $/ \%$ \\
\hline \multirow[t]{4}{*}{373} & Ll & $4.85 \mathrm{E}-5 / \mathrm{H}$ & 5.20 \\
\hline & CPE1-T & $3.03 \mathrm{E}-11 / \mathrm{F}$ & 0.88 \\
\hline & CPEI-P & $0.88 / \mathrm{rad}$ & 0.56 \\
\hline & RI & $8.04 \mathrm{E} X / \Omega L$ & N/A \\
\hline \multirow[t]{3}{*}{473} & Ll & 6.82E-5/H & 6.60 \\
\hline & CPE1-T & $8.60 \mathrm{E}-11 / \mathrm{F}$ & 4.19 \\
\hline & CPEI-P & $0.79 / \mathrm{rad}$ & 0.42 \\
\hline & & & N/A \\
\hline \multirow{2}{*}{573} & $\mathrm{R} 1$ & $3.74 / \Omega$ & N/A \\
\hline & L1 & $1.86 \mathrm{E}-6 / \mathrm{H}$ & 2.14 \\
\hline \multirow{2}{*}{673} & $\mathrm{R} 1$ & $2.44 / \Omega$ & 1.12 \\
\hline & L1 & $1.96 \mathrm{E}-6 / \mathrm{H}$ & 2.24 \\
\hline
\end{tabular}

Table IV. The least square fit results for the complex impedance of $\alpha-\mathrm{Fe}_{2} \mathrm{O}_{3}$ sensor under different temperatures and synthetic air atmosphere.

\begin{tabular}{|c|c|c|c|}
\hline Temperature/K & $\begin{array}{l}\text { Equivalent circuit } \\
\text { elements }\end{array}$ & Value/unit & Error $/ \%$ \\
\hline \multirow[t]{4}{*}{373} & Ll & $7.55 \mathrm{E}-5 / \mathrm{H}$ & 6.12 \\
\hline & CPE1-T & $2.18 \mathrm{E}-11 / \mathrm{F}$ & 3.55 \\
\hline & CPE1-P & $0.88 / \mathrm{rad}$ & 0.36 \\
\hline & R1 & $5.77 \mathrm{E} 8 / \Omega 2$ & N/A \\
\hline \multirow[t]{4}{*}{473} & Ll & $4.14 \mathrm{E}-5 / \mathrm{H}$ & 4.87 \\
\hline & CPE1-T & $8.16 \mathrm{E}-12 / \mathrm{F}$ & 2.55 \\
\hline & CPEI-P & $0.96 /$ rad & 0.21 \\
\hline & $\mathrm{R} 1$ & $1.70 \mathrm{E} 5 / \Omega$ & N/A \\
\hline \multirow[t]{4}{*}{573} & L1 & $4.25 \mathrm{E}-5 / \mathrm{H}$ & 6.97 \\
\hline & CPE1-T & $1.38 \mathrm{E}-11 / \mathrm{F}$ & 2.94 \\
\hline & CPE1-P & $0.94 / \mathrm{rad}$ & 0.18 \\
\hline & RI & $4.12 \mathrm{E} 6 / \Omega$ & N/A \\
\hline \multirow[t]{4}{*}{673} & $\mathrm{Ll}$ & $2.77 \mathrm{E}-5 / \mathrm{H}$ & 5.75 \\
\hline & CPE 1-T & $8.75 \mathrm{E}-12 / \mathrm{F}$ & 2.30 \\
\hline & CPE1-P & $0.99 / \mathrm{rad}$ & 0.14 \\
\hline & R1 & $1.85 \mathrm{E} 5 / \Omega$ & N/A \\
\hline
\end{tabular}

property are governed by the large concentration of the grain boundaries, due to nano-size of the grains, and by the temperature. Therefore, we assume that the conductivity of the material is of electronic origin, Arrhenius activated and affected by the interaction of hydrogen with the sensor material. Strong variation of conductivity versus temperature suggests that the conductivity can be explained as an Arrhenius activated process as illustrated in Figure 9. Solid and dotted curves show the variation of the conductivity under synthetic air and hydrogen atmosphere, respectively. The variation of conductivity $\sigma$ with temperature is interpreted using the Arrhenius equation:

$$
\sigma=\sigma_{0} \exp \left(-\frac{E_{a}}{k T}\right)
$$

where: $\sigma$ is the conductivity, $E_{\mathrm{a}}$ is the activation energy for electrical conduction, and $k$ is the Boltzmann constant.

Table V. The least square fit results for the complex impedance of $\alpha-\mathrm{Fe}_{2} \mathrm{O}_{3}$ sensor under different temperatures and hydrogen atmosphere.

\begin{tabular}{lccc}
\hline Temperature/K & $\begin{array}{c}\text { Equivalent circuit } \\
\text { elements }\end{array}$ & Value/unit & Error/\% \\
\hline 373 & L1 & $4.77 \mathrm{E}-5 / \mathrm{H}$ & 5.02 \\
& CPE1-T & $9.45 \mathrm{E}-12 / \mathrm{F}$ & 2.56 \\
& CPE1-P & $0.95 / \mathrm{rad}$ & 0.22 \\
& $\mathrm{R} 1$ & $1.04 \mathrm{E} 9 / \Omega$ & $\mathrm{N} / \mathrm{A}$ \\
473 & $\mathrm{~L} 1$ & $4.19 \mathrm{E}-5 / \mathrm{H}$ & 10.20 \\
& $\mathrm{CPE} 1-\mathrm{T}$ & $3.48 \mathrm{E}-11 / \mathrm{F}$ & 4.30 \\
& $\mathrm{CPE} 1-\mathrm{P}$ & $0.89 / \mathrm{rad}$ & 2.35 \\
& $\mathrm{R} 1$ & $3.35 \mathrm{E} 5 / \Omega$ & $\mathrm{N} / \mathrm{A}$ \\
573 & $\mathrm{R} 1$ & $2.60 / \Omega$ & 1.00 \\
& $\mathrm{~L} 1$ & $1.9 \mathrm{E}-6 / \mathrm{H}$ & 2.0 \\
673 & $\mathrm{R} 1$ & $2.39 / \Omega$ & 1.03 \\
& $\mathrm{~L} 1$ & $1.90 \mathrm{E}-6 / \mathrm{H}$ & 2.06 \\
\hline
\end{tabular}


The trend of the conductivity under air atmosphere presented as a function of temperature can be approximated to some extent by an Arrhenius law. Iron oxides show a typical semiconductor-like behavior in the ranges presented in Figure 9(a).

The water molecules from the humidity prevalent under ambient conditions can occupy many active sites on nanoparticles. Those active sites are a manifestation of the defect structure and oxygen deficiency. Oxygen vacancies constitute unpaired valence electrons and form electrically active sites, which are saturated by the chemisorption or physisorption of the surrounding molecules including water vapor. When the water vapor is present in the atmosphere the negatively charged hydroxyl group from the water molecule can be attached to the positively charged cation site and positively charged hydrogen to the anionic site satisfying the valence and charge neutrality. Thus, the adsorbed water molecules cause mass transfer associated with the ion movement towards electrode and sample connection. ${ }^{26,32}$ This is observed at a low frequency trace in the impedance spectra at the ambient

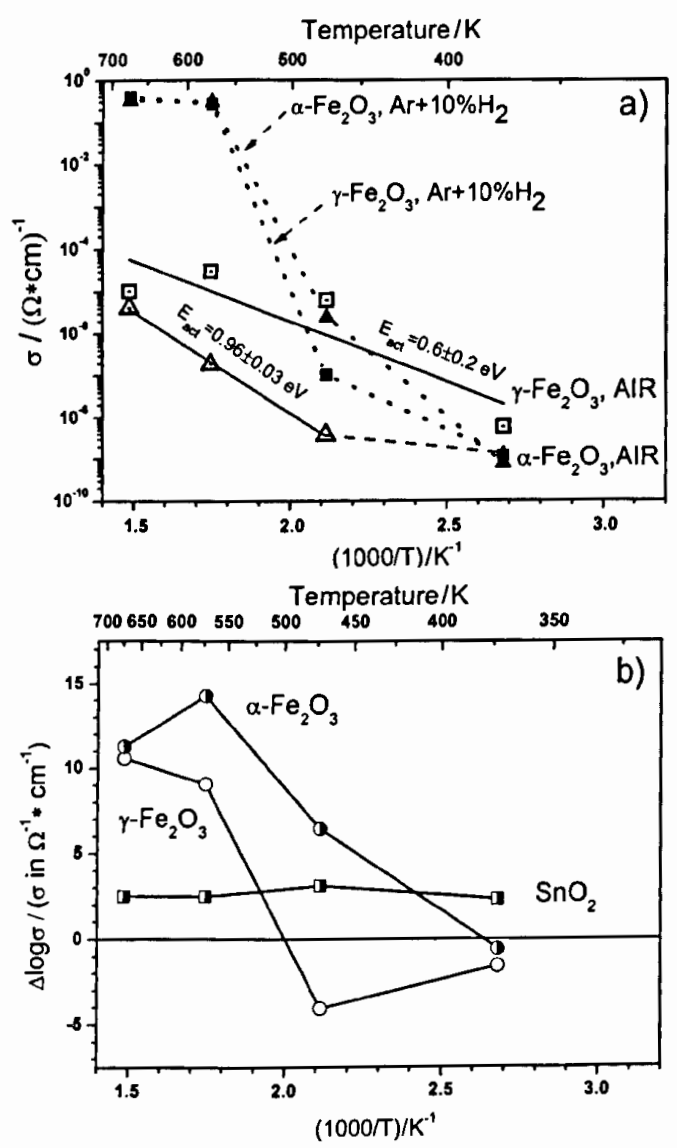

Fig. 9. Conductivity changes of both $\mathrm{Fe}_{2} \mathrm{O}_{3}$ samples upon exposure to synthetic air and hydrogen atmosphere $\left(\mathrm{Ar}+10 \% \mathrm{H}_{2}\right)$ as a function of temperature (a) and relative conductivity changes as a function of temperature upon exposure to air and hydrogen atmospheres in comparison to $\mathrm{SnO}_{2}$ reference (b). temperature measurement under air and hydrogen atmosphere. Physisorption is based only on weak Van der Waals forces and does not significantly affect the transport properties of the sensor material. ${ }^{36}$ From the electrical point of view, chemisorbed hydroxyl groups act as donor levels. After injection of the electrons to the conduction band, the depletion layer (space charge region of positively charged ions near the surface) is reduced and the conductivity of the material increases. ${ }^{36,37}$ Rise of the temperature from $298 \mathrm{~K}$ to $373 \mathrm{~K}$ causes desorption of the water molecules from the surface, and hence the conductivity of the material decreases. This manifests as a large semicircle in the impedance spectrum in Figure 4 for the measurements at $373 \mathrm{~K}$. Further rising of temperature increases the charge carrier concentration in the material due to electron transfer from the valence to the conduction band, and induces additional oxygen-vacancies-related states within the band gap. This increases the conductivity considerably and can be seen particularly as admittance spectra for $573 \mathrm{~K}$ and $673 \mathrm{~K}$ under hydrogen atmosphere. The interaction of the metal oxide $n$-type semiconductor with the reducing gas can be explained to a wide extent with Morrison's mechanism. ${ }^{28}$ The first stage of this mechanism is the chemisorption of the oxygen gas molecules on the surface of material, which leads to the extraction of electrons from the material. This causes a reduction of the electron concentration near the surface, which can be considered as the creation of depletion layer of the positively charged ions. Consequently the conductivity decreases. Because gas sensors typically operate at elevated temperatures, where the concentration of adsorbed oxygen ion species decreases, it can be assumed that adsorbed oxygen ions can be desorbed by the electron injection. This initiates the second stage of the gas-semiconductor interaction. The desorbed surface species can react then with the reducing agent, which drives an increase of the conductivity and a decrease of the ion surface density.

When the conductivity changes as a function of temperature are considered, three ranges that can be ascribed to different processes are distinguishable (Fig. 9(a)). The first process has already been described above as desorption of water at $373 \mathrm{~K}$-resulting in the decrease of the conductivity. Second, in the range $373-573 \mathrm{~K}$ for $\gamma-\mathrm{Fe}_{2} \mathrm{O}_{3}$ and $473-673 \mathrm{~K}$ for $\alpha-\mathrm{Fe}_{2} \mathrm{O}_{3}$ a typical semiconductor-like behavior is observed with an Arrhenius characteristic. The conductivity increases with temperature rise. The behavior in the last range for $T>573 \mathrm{~K}$ can be interpreted as the conversion of oxygen ions as was reported by Yamazoe et al. (Ref. [38]) for tin oxide, as well as by Morrison's (Ref. [28]) general model for metal oxide semiconductors. At elevated temperatures, the dominant ion species in the form of $\mathrm{O}_{2}^{-}$are converted into highly active $\mathrm{O}^{-}$ions. They can create more surface states by capturing electrons from the conduction band, and thus a slight decrease of the conductivity is observed. The estimated activation energies for 
the conductivity under air atmosphere are: $0.6 \pm 0.2 \mathrm{eV}$ for $\gamma-\mathrm{Fe}_{2} \mathrm{O}_{3}$ and $0.96 \pm 0.03 \mathrm{eV}$ for $\alpha-\mathrm{Fe}_{2} \mathrm{O}_{3}$, which is similar to those, reported in Ref. [29], [31]. The similar estimation of the activation energy for the conductivity under hydrogen atmosphere gives unrealistic high values for both samples. This is attributed to the reduction of the material. The estimated values are corresponding to the calculated particle size. Aroutiounian et al. (Ref. [29]) and Boudjemaa et al. (Ref. [31]) explained the large activation energies with the presence of the small amount of bivalent iron ions $\mathrm{Fe}^{2+}$. The conduction in $\mathrm{Fe}_{2} \mathrm{O}_{3}$ is affected by electron hopping from $\mathrm{Fe}^{2+}$ to $\mathrm{Fe}^{3+}$ and this transfer can be made here only at high operating temperatures. The presence of $\mathrm{Fe}^{2+}$ in the maghemite or hematite containing samples, where $\mathrm{Fe}$ is mainly in the $3+$ oxidation state, can be expected when the sample is kept at high temperatures under reducing conditions, such as at $573 \mathrm{~K}$ under hydrogen atmosphere.

Figure 9(b) shows the relative changes of the conductivity of both $\mathrm{Fe}_{2} \mathrm{O}_{3}$ samples upon exposure to air and hydrogen atmosphere as a function of temperature in comparison to the reference $\mathrm{SnO}_{2}$ sample (crystallite size $d_{\mathrm{XRD}}=$ $10.89 \mathrm{~nm})$. It is striking that both $\mathrm{Fe}_{2} \mathrm{O}_{3}$-based sensors have stronger variation in the conductivity, i.e., a larger dynamic range than the $\mathrm{SnO}_{2}$ reference material, strongly suggesting that FSS-made $\mathrm{Fe}_{2} \mathrm{O}_{3}$ can give better response when operating as a gas sensor for hydrogen detection, than FSS-made $\mathrm{SnO}_{2}$. Non-stoichiometry in the form of oxygen vacancies and charges injected on the surface from the interaction with reducing agent are the main sources of the electrons in FSS-made $\mathrm{Fe}_{2} \mathrm{O}_{3}$. The oxygen vacancies introduce shallow donor levels in the band gap, which can contribute to the conduction band inducing conductivity (charge carriers donated from the surface reactions). In consequence, both $\mathrm{Fe}_{2} \mathrm{O}_{3}$ samples are sensitive to hydrogen exposure.

The conduction mechanism in $\alpha-\mathrm{Fe}_{2} \mathrm{O}_{3}$ has been under debate since early $1950 \mathrm{~s}$. The two primary models which are considered are the band-like transport of large whiarons, or small polaron hopping. ${ }^{39}$ In our study two different forms of $\mathrm{Fe}_{2} \mathrm{O}_{3}$ were investigated: as-synthesized $\gamma-\mathrm{Fe}_{2} \mathrm{O}_{3}$ and post-treated under air atmosphere $\alpha-\mathrm{Fe}_{2} \mathrm{O}_{3}$. They exhibited different type of conductivity: $n$-type and -type. This is demonstrated in the gas sensor response. It was already shown that the electrical properties of $\alpha-\mathrm{Fe}_{2} \mathrm{O}_{3}$ depend on the precursors and synthesis conditions, which affect the important defect chemistry. Morin (Ref. [40]) as well as Gurlo et al. (Ref. [2]) reported that $\alpha-\mathrm{Fe}_{2} \mathrm{O}_{3}$ annealed in air or hydrogen show $n$-type and $p$-type conductivity, respectively. It is generally known that the type of conductivity depends on the dominant defects in the structure, including oxygen vacancies $\mathrm{V}_{o}$ and extra electrons $e^{\prime}$, which produce $n$-type conductivity Eq. (4):

$$
\mathrm{Fe}_{2} \mathrm{O}_{3} \leftrightarrow 2 \mathrm{Fe}_{\mathrm{Fe}}^{\mathrm{x}}+3 \mathrm{~V}_{\mathrm{O}}^{\bullet \bullet}+6 e^{\prime}+\frac{3}{2} \mathrm{O}_{2} \uparrow
$$

Excess of oxygen creates iron vacancies $\mathrm{V}_{\mathrm{Fe}}^{\mathrm{N}-}$ and electron holes $h^{\bullet}$, causing $p$-type conductivity Eq. (5):

$$
\frac{3}{2} \mathrm{O}_{2} \leftrightarrow 2 \mathrm{~V}_{\mathrm{Fe}}^{\mathrm{N}-}+2 \mathrm{~N} h^{\bullet}+3 \mathrm{O}_{\mathrm{O}} \quad \mathrm{N}=2 \text { or } 3
$$

\subsection{Gas Sensor Response}

The sensor response of both polymorphic $\mathrm{Fe}_{2} \mathrm{O}_{3}$ samples versus hydrogen was measured for a very wide range of gas concentrations covering $1000-25000 \mathrm{ppm}$. The dynamic changes in the electrical resistance $R$ as a function of time under hydrogen atmosphere (1000$25000 \mathrm{ppm}$ ) and the response time of the sensors operating at $573 \mathrm{~K}$ are presented in Figure 10.

The response time is here defined as the time required for the variation in resistance to reach $95 \%$ of the maximum value after the gas was injected. The relative changes of the resistance are indeed significant. The sensor signal is stable in the entire concentration range. The response time of the sensor for the best working conditions remains below $3 \mathrm{~min}$. Recovery time seems to be also promisingly short. This material is hence attractive for sensor applications. The gas sensor response $S$ towards hydrogen as a
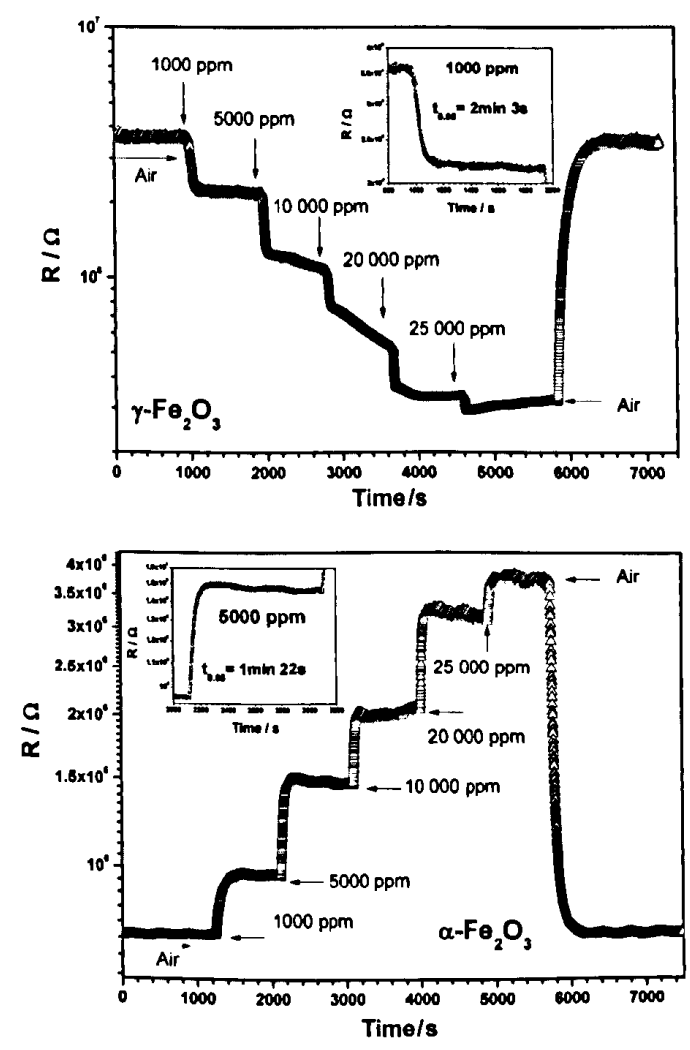

Fig. 10. Dynamic changes in the electrical resistance $R$ of FSS-made $\mathrm{Fe}_{2} \mathrm{O}_{3}$ based sensors: $\gamma$ - $\mathrm{Fe}_{2} \mathrm{O}_{3}$ (left) and $\alpha-\mathrm{Fe}_{2} \mathrm{O}_{3}$ (right) at $573 \mathrm{~K}$ as a function of time upon exposure to hydrogen containing atmosphere (1000-25000 ppm $\mathrm{H}_{2}$ ) after equilibrating the electrical resistance under air atmosphere. Insets show the response time of the sensor. 
function of the hydrogen concentration for selected operating temperatures is shown in the Figure 11. $S<1$ denotes $n$-type conductivity and $S>1$ denotes $p$-type conductivity. The sensor based on $\gamma-\mathrm{Fe}_{2} \mathrm{O}_{3}$ shows $n$-type conductivity up to $573 \mathrm{~K}$, and $\alpha-\mathrm{Fe}_{2} \mathrm{O}_{3} p$-type conductivity, what can be clearly seen from the direction of relative changes of resistance. Change of the type of conductivity from $n$-type to $p$-type with temperature was observed. At $673 \mathrm{~K} \gamma-\mathrm{Fe}_{2} \mathrm{O}_{3}$ sensor sample switched the direction of resistance changes and became a $p$-type semiconductor. This can be attributed to the phase transformation from $\gamma-\mathrm{Fe}_{2} \mathrm{O}_{3}$ to $\alpha-\mathrm{Fe}_{2} \mathrm{O}_{3}$ (see $\mathrm{XRD}$ patterns, Fig. 1). The strongest response was measured for the sensor operating at $523 \mathrm{~K}$. Increase of operating temperature is accompanied by decrease of sensor response. Our sensor can actually compete with sensors reported in the literature, $1,2,5,8,12,14$ although it should be noted that those reference sensors had been prepared with different methods and different sensor technologies. In addition their sensor performance has been based on different definitions for sensor response. For fair comparison we thus applied either definition, where necessary. The thick film gas sensor reported in Ref. [1] was based on $\alpha-\mathrm{Fe}_{2} \mathrm{O}_{3}$ modified with tetravalent metal ions and $\mathrm{Pd}$. The as-synthesized gas sensor showed only slightly higher sensor response. Its sensor response towards $1000 \mathrm{ppm} \mathrm{H}_{2}$ during operation at $623 \mathrm{~K}$ was $36 \%$, whereas we show a $91 \%$ sensor response based on unmodified bulk $\alpha-\mathrm{Fe}_{2} \mathrm{O}_{3}$ operating at the even lower temperature of $523 \mathrm{~K}$. The tubular hydrogen sensor presented in Ref. [12] was based on pure and $\mathrm{Cd}$-doped $\gamma-\mathrm{Fe}_{2} \mathrm{O}_{3}$. Sensors were operating at $513 \mathrm{~K}$ and $543 \mathrm{~K}$, respectively. The sensor response for $1000 \mathrm{ppm} \mathrm{H}_{2}$ was approximately 2.5 for the pure material and approximately 4 for the modified material. The sensor response for our unmodified bulk $\gamma-\mathrm{Fe}_{2} \mathrm{O}_{3}$ was 5.45 at $523 \mathrm{~K}$. The tubular gas sensor in Ref. [14] was based on $\gamma$ - $\mathrm{Fe}_{2} \mathrm{O}_{3}$ modified with $\mathrm{Ag}_{2} \mathrm{O}$. The sensor response for $1000 \mathrm{ppm} \mathrm{H}_{2}$ at $593 \mathrm{~K}$ was below 20. In summary, sensors based on FSS-synthesized $\gamma-\mathrm{Fe}_{2} \mathrm{O}_{3}$ and post-treated $\alpha-\mathrm{Fe}_{2} \mathrm{O}_{3}$ in the bulk form showed overall better hydrogen

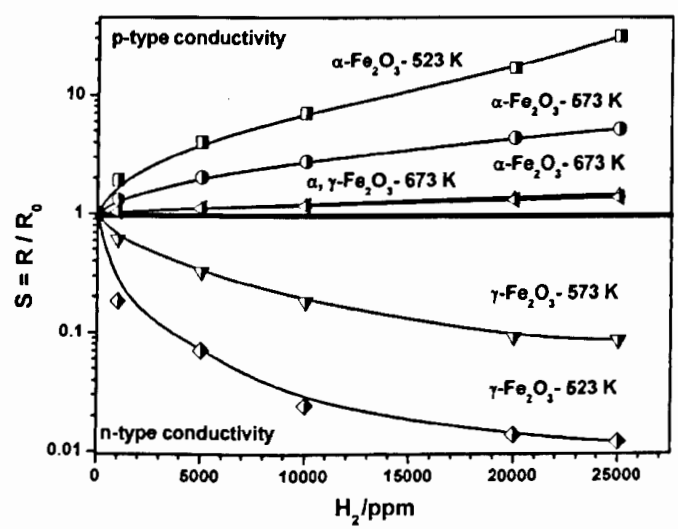

Fig. 11. Change of the relative resistance of $\gamma-\mathrm{Fe}_{2} \mathrm{O}_{3}$ and $\alpha-\mathrm{Fe}_{2} \mathrm{O}_{3}$ as a function of hydrogen concentration. sensing performance. The optimum operating temperature of our sensors was lower and/or similar to comparable sensors readily reported in literature. The curvature of the sensor characteristics $S\left(c_{\mathrm{H} 2}\right)$ suggests that our material can perform efficiently as a hydrogen sensor in a wide range of concentrations even up to $20000 \mathrm{ppm}$. However, it seems that together with increase of gas concentration the sensor response tends to a saturation value. The $S$ values for each concentration differ sufficiently to be distinguishable. This feature can be utilized in the calibration of the gas sensor.

\section{CONCLUSIONS}

Nanoscaled iron oxide with maghemite phase was synthesized with the FSS technique from ferrocene solution in benzene. Thermal post-treatment induced the phase transformation towards hematite, with improved crystallinity. The direction of the dynamic changes in the electrical resistance under hydrogen exposure showed that assynthesized $\gamma-\mathrm{Fe}_{2} \mathrm{O}_{3}$ and post-treated $\alpha-\mathrm{Fe}_{2} \mathrm{O}_{3}$ semiconductors are of different type of conductivity. $\gamma-\mathrm{Fe}_{2} \mathrm{O}_{3}$ is an $n$-type semiconductor up to $573 \mathrm{~K}$ and $\alpha-\mathrm{Fe}_{2} \mathrm{O}_{3}$ is a $p$-type semiconductor. It was shown that the conductivity of both materials has an electronic character. The presence of trap states located in the region adjacent to grain boundaries is detrimental for the sensor functionality. The conduction process was thermally activated and affected by the interaction of the hydrogen with the sensor surface. The fundamental value of the Debye screening length for gas sensor material was found to be about $27 \mathrm{~nm}$ for $\gamma-\mathrm{Fe}_{2} \mathrm{O}_{3}$ and about $16 \mathrm{~nm}$ for $\alpha-\mathrm{Fe}_{2} \mathrm{O}_{3}$. FSS-made $\mathrm{Fe}_{2} \mathrm{O}_{3}$ fulfill the assumption of $d \leq \lambda_{\mathrm{D}}$ for the best performing sensor material. Significant change of the conductivity and the activation energy upon exposure to ambient atmospheres (to air and to hydrogen) in comparison to FSS-made $\mathrm{SnO}_{2}$ used as reference was observed. Iron oxide-based ( $\gamma$ and $\alpha$ ) sensor response towards hydrogen showed that, both samples exhibited strong and fast response in the wide concentration range from 1000-20000 ppm. The optimum operating temperature was found to be $523 \mathrm{~K}$, and the sensor response was moderately short making this material attractive for gas sensor applications.

Acknowledgment: The financial support of Regional Development of the European Union Programme for Technological Development, grant No. POIG.01.03.01-02002/08-00 and by the PhD School Switzerland-Poland is acknowledged.

\section{References and Notes}

1. W.-Y. Chung and D.-D. Lee, Thin Solid Films 200, 329 (1991).

2. A. Gurlo, M. Sahm, A. Oprea, N. Barsan and U. Weimar, Sens. Actuators B 102, 291 (2004).

3. T. Kim and B. Guo, J. Ind. Eng. Chem., 17, 158 (2011). 
4. M. Pelino, C. Cantalini, H.-T. Sun, and M. Faccio, Sens. Actuators $B$ 46, 186 (1998)

5. N. Rezlescu, C. Doroftei, E. Rezlescu, and M.L. Craus, Rom. Rep. Phys. 60, 1041 (2008).

6. K. Suri, S. Annapoorni, A. K. Sarkar, and R. P. Tandon, Sens. Actuators B 81, 277 (2002).

7. H. Tang, M. Yan, H. Zhang, S. Li, X. Ma, M. Wang, and D. Yang, Sens. Actuators B 114, 910 (2006).

8. A. A. Vasiliev and M. A. Polykarpov, Sens. Actuators B 7, 626 (1992).

9. Y. Wang, Y. Wang, J. Cao, F. Kong, H. Xia, J. Zhang, B. Zhu, S. Wang, and S. Wu, Sens. Actuators B 131, 183 (2008).

10. S.-Y. Zhao, H.-Y. Ma, S.-H. Chen, Ch. T. Wang, and D.-G. Li, J. Electrochem. Soc. 149, 169 (2002).

11. Y.C. Lee, Y.-L. Chueh, C.-H. Hsieh, M.-T. Chang, L.-J. Chou, Z. L. Wang, Y. -W. Lan, C.-D. Chen, H. Kurata, and S. Isoda, Small 3, 1356 (2007).

12. Z. Jing, Y. Wang, and S. Wu, Sens. Actuators B 113, 177 (2006).

13. M. N. Rumyantseva, V. V. Kovalenko, A. M. Gaskov, T. Pagnier, D. Machon, J. Arbiol, and J. R. Morante, Sens. Actuators B 109, 64 (2005).

14. J. Wang, M. Tong, X. Wang, Y. Ma, D. Liu, J. Wu, D. Gao, and G. Du, Sens. Actuators B 84, 95 (2002).

15. T. Sähm, L. Mädler, A. Gurlo, N. Barsan, S. E. Pratsinis, and U. Weimar, Sens. Actuators B 98, 148 (2004).

16. R. Strobel and S. E. Pratsinis, J. Mater. Chem. 17, 4743 (2007).

16. A. Teleki, S. E. Pratsinis, K. Kalyanasundaram, and P. I. Gouma, Sens. Actuators B 119,683 (2006).

18. K. K. Akurati, A. Vital, J.-P. Dellemann, K. Michalow, T. Graule, D. Ferri, and A. Baiker, Appl. Catal. B 79, 53 (2008).

9. K. A. Michalow, A. Vital, A. Heel, T. Graule, F. A. Reifler, A. Ritter, K. Zakrzewska, and M. Rekas, J. Adv. Oxid. Technol. 11, 56 (2008).

20. R. M. Comell, U. Schwertmann, The Iron Oxides: Structure, Properties, Reactions, Occurrences and Uses, 2nd edn., Wiley-Vch, Weinheim (2003).
21. A. Braun, F. E. Huggins, K. E. Kelly, B. S. Mun, S. N. Ehrlich, and G. P. Huffman, Carbon 44, 2904 (2006).

22. W. C. Hinds, Aerosol Technology: Properties, Behaviour and Measurements of Airborn Particles, 2nd edn., John Wiley and Sons, New York (1999).

23. N. H. Al-Hardan, M. J. Abdullah, and A. A. Aziz, Int. J. Hydrogen Energy 35, 4428 (2010).

24. Ch. Demetry and X. Shi, Solid State Ionics 118, 271 (1999).

25. A. Weibel, R. Bouchet, and P. Knauth, Solid State Ionics, 177, 229 (2006).

26. N. Barsan and U. Weimar, J. Electroceram. 7, 143 (2001).

27. E. Comini, Anal. Chim. Acta 568, 28 (2006).

28. S. R. Morrison, Sens. Actuators 11, 283 (1987).

29. V. M. Aroutiounian, V. M. Arakelyan, G. E. Shahnazaryan, H. R. Hovhannisyan, H. Wang, and J. A. Turner, Solar Energy 81, 1369 (2007).

30. E. Barsoukov and J.R Macdonald, Impedance spectroscopy: Theory, Experiment, and Applications, 2nd edn., Wiley and Sons, New Jersey (2005).

31. A. Boudjemaa, S. Boumaza, M. Trari, R. Bouarab, and A. Bouguelia, Int. J. Hydrogen Energy 34, 4268 (2009).

32. O. K. Varghese and L. K. Malhota, J. Appl. Phys. 87, 7457 (2000).

33. J. W. Orton and M. J. Powell, Rep. Prog. Phys. 43, 1263 (1980).

34. S. S. Shinde, R. A. Bansode, C. H. Bhosale, K. Y. Rajpure, J. Nanotechnol. 32, 130011 (2011).

35. J. A. Glasscock, P. R. F. Barnes, I. C. Plumb, A. Bendavid, and P. J. Martin, J. Phys. Chem. C 111, 16477 (2007).

36. W. Gopel, Prog. Surf. Sci. 20, 9 (1985).

37. N. Barsan and R. Ionescu, Sens. Actuators B 12, 71 (1993).

38. N. Yamazoe, J. Fuchigami, M. Kishikawa, and T. Seiyama, Surf. Sci. 86,335 (1979).

39. K. M. Rosso, M. A. Dayle, and M. Dupuis, J. Chem. Phys. 118, 6455 (2003).

40. F. J. Morin, Phys. Rev. 83, 1005 (1951).

Received: 18 October 2011. Accepted: 2 April 2012. 